\section{Consumer Preferences for Price, Color Harmony, and Care Information of Container Gardens}

\author{
Shannon C. Mason ${ }^{1}$, Terri W. Starman ${ }^{2,5}$, and R.D. Lineberger ${ }^{3}$ \\ Department of Horticultural Sciences, Texas A \& M University, 2133 TAMU, \\ College Station, TX 77843-2133
}

Bridget K. Behe ${ }^{4}$

Department of Horticulture, Michigan State University, Plant and Soil Sciences Building, East Lansing, MI 48824-1325

Additional index words. conjoint analysis, container gardening, Internet survey, Likert scale, Web survey

\begin{abstract}
Retail sales of container gardens have increased dramatically in recent years, rising $8 \%$ from 2004 to 2005 , to $\$ 1.3$ billion. The objective of this study was to determine consumer preferences for three attributes of container gardens; color harmony, price, and amount of care information provided with the purchase. A hierarchical set of levels for each attribute was used in a $3 \times 3 \times 3$ factorial conjoint analysis. A Web-based survey was conducted on 18 Oct. 2006 with 985 respondents. Survey participants were asked to complete a series of questions on a 7-point Likert scale. Survey participants also answered questions about past experiences with and future purchase intentions of container gardens as well as demographics. The three attributes accounted for $99.8 \%$ of the variance in container garden preference. Relative importance decreased from price $\mathbf{7 1 \%}$ ) to amount of care information $(\mathbf{2 3 \%})$ to color harmony $(6 \%)$. Survey participants preferred a container garden with a price point of $\mathbf{\$ 2 4 . 9 9}$, extensive care information, and complementary color harmony. A large portion (76\%) of participants in this study indicated that they would be more likely to purchase a container garden if extensive care information was included with the purchase and $85 \%$ of participants said they would be willing to visit an Internet Web site that would provide more information on how to care for and maintain a container garden. Results of this study show that there is a potential to increase the value of a container garden through providing educational material with the purchase.
\end{abstract}

Container gardening is one of the more promising categories of the lawn and garden market (Miller, 2001). Twenty-nine million households participated in container gardening in 2005 , five million more households than the previous 5-year average of 24 million. Total retail sales for container gardening in 2005 were $\$ 1.3$ billion, 3\% more than the 5 -year

Received for publication 2 Oct. 2007. Accepted for publication 20 Nov. 2007.

This research was funded in part by the Texas Agricultural Experiment Station.

We thank Calloway's Nursery for providing incentives to participants and for assisting in administering our survey to their customers. We also thank Doug Welsh for allowing us to survey Texas Master Gardeners.

Mention of a trademark, proprietary product, or vendor does not constitute a guarantee or warranty of the product by the author, Texas A \& M University, or the Texas Agricultural Experiment Station and does not imply its approval to the exclusion of other products or vendors that also may be suitable.

${ }^{1}$ Graduate Student.

${ }^{2}$ Associate Professor of Floriculture.

${ }^{3}$ Professor and Webmaster of the Aggie Horticulture Network.

${ }^{4}$ Professor.

${ }^{5}$ To whom reprint requests should be addressed; e-mail tstarman@tamu.edu. with some success.
Conjoint analysis is a technique that allows for the analysis of consumer purchases, gives insight to the relative importance of product attributes, defines product quality on the consumer's level, and allows the industry to adjust marketing strategies (Gaasbeek and Bouwman, 1991). It is typically less biased than focus groups or traditional direct question-and-answer surveys because it embeds the topic of question within the context of an issue for a less direct, more natural approach to a topic (Moskowitz et al., 2004). It also allows researchers to simultaneously investigate a number of product attributes and determine the relative importance of each attribute in the consumer's preference (Frank et al., 2001). Conjoint analysis has been used to determine consumer preferences for bell peppers (Frank et al., 2001), geraniums (Behe et al., 1999), tomatoes (Simonne et al., 2006), and tabletop Christmas trees (Behe et al., 2005) among other horticultural and floricultural applications.

Many industries today conduct market research using the Internet because there are several advantages to this method over mail or fax surveys. Web-based surveys are a fast method in which high-quality images can be used. Thousands of surveys can be transmitted at a time, they are automatically coded, and the data are collected in a costeffective manner (Cobanoglu et al., 2001). Advantages of Web-based surveys according to McCullough (1998) are that they are potentially faster to conduct than telephone or face-to-face interviews, generate more accurate information with less human error, and are cheaper by several magnitudes because less labor is needed to create, deliver, and analyze the survey. Internet access by adults at home or work was estimated to be 210 million in the United States of a population estimated at 300 million, or $69.6 \%$ (Internet World Stats, 2006). The inclusion of cash and noncash incentives for participating in consumer surveys can increase response rates significantly (Cobanoglu et al., 2001). An Internet study used a $\$ 5.00$ e-coupon from Amazon.com in exchange for the consumer completing the survey and researchers were able to collect 743 usable surveys with this method (Dennis et al., 2004). In addition, Hicks et al. (2005) and Behe (2006) also provided incentives to participants for participating in their surveys.

The objective of this study was developed to determine consumer preferences for price, color harmony, and amount of care information provided with the purchase of container gardens using a Web-based survey. This research was also conducted to determine characteristics of container garden users and what motivated them to purchase.

\section{Materials and Methods} (Singh, 1999). Marketing research in the floriculture industry was summarized by Behe (1993) and found to be very limited. Since that time, marketing efforts have increased 
rooted liners (84 rooted liners/tray) were received from Proven Winners (EuroAmerican Propagators, Bonsall, CA) on 9 Mar. 2006. The liners were planted on 10 and 14 Mar. All liners were planted in soilless media (Pro Mix BX; Premier Brands, Quakertown, $\mathrm{PA})$ in $10.6-\mathrm{cm}(480 \mathrm{~mL})$ standard round plastic pots (Dillen Products, Middlefield, $\mathrm{OH})$. From arrival of liners until 15 Mar., plants were hand-watered with reverse osmosis water. Beginning on 17 Mar., plants were fertilized at each irrigation with $20 \mathrm{~N}-3.4 \mathrm{P}$ 16.6K (Peter's Professional; Scotts-Sierra Horticultural Products Company, Marysville, $\mathrm{OH})$ water-soluble fertilizer at $200 \mathrm{mg} \cdot \mathrm{L}^{-1} \mathrm{~N}$.

On 3 Apr., plants grown in individual pots were planted together in $36.2-\mathrm{cm}(12.7 \mathrm{~L})$ plastic pots (Dillen Products, Middlefield, $\mathrm{OH})$ using a container garden design. The planting design was according to plant forms, heights, and textures. The cultivars of ornamental sweetpotato [Ipomoea batatas (L.) J.de Lamarck], calibrachoa (Calibrachoa $\times$ hybrida Lave Lex), and coleus [Solenostemon scutellariodides (L.) L.E.W. Codd] were varied in the design to create three color harmonies (Fig. 1). Color harmonies are pleasing ways to mix colors together using combinations of colors from the color wheel (Starman and Pufahl, 2002). The angelonia (Angelonia angustifolia $\mathrm{G}$. Bentham 'Angelface Blue'), heliotrope (Heliotropium aborescens L. 'Nagano'), and coral bells (Heuchera hybrid G. Engelmann 'Velvet Night') used in the design were the same for all containers. Until photographs were taken, plants within the containers were pruned as needed to increase branching, maintain proportion, and prevent shading among the different species. Pruning of plants in the containers was performed on a 10- to 15-d schedule.

Digital photographs were taken weekly beginning on 17 Apr. 2006 until 27 July of each container garden with a Sony Mavica camera (MVC-CD1000, Park Ridge, NJ). Photographs taken on 21 Apr. 2006 were used in the conjoint analysis section of the survey. All photographs taken after this date were used to create progressions of plant growth and to demonstrate results of pruning. Photographs were scrutinized and compared with each other to find one container garden from each color harmony that was nearly identical, i.e., the number of flowers on angelonia, heliotrope, and calibrachoa were similar and the vigor of the other plants was indistinguishable.

A survey was developed using several photographs of the container gardens. In addition to questions regarding gardening experiences and future behavioral intentions with container gardening, a conjoint study was conducted to determine the relative importance of three attributes of container gardens: price, color harmony, and amount of care information. We also used the identical three survey questions, which measured delight, and two questions, which measured repurchase intentions, taken from a study by Hicks et al. (2005) showing that customer delight, a stronger emotion than customer satisfaction, increased the likelihood that a customer would make a repeat purchase of a flowering indoor potted plant. We wanted to discern if the model was the same for the purchase of a mixed container garden. Approval was granted before start of data collection in Fall 2006 by Texas A \& M University's Institutional Review Board to conduct research with human subjects.

Macromedia Dreamweaver (Version 8; San Jose, CA) Web page creation software was used to create the Internet survey. A database was created using FileMaker Pro (Version 6; Santa Clara, CA) to accurately record participants' survey responses. Some photographs and photograph progressions were refined with Adobe Photoshop (Version 6.0; San Jose, CA). The survey database was hosted online at $<$ http://floriculture.tamu. edu:7998 $>$ (no longer open) on 18 Oct.

Consumer preferences were determined using an additive model in which utility scores, also defined as part-worths, for each factor (color harmony, price, and amount of care information) were added to form the overall preference for a container garden. For each of these factors, we identified a hierarchical set of levels to investigate. The color harmonies were monochromatic, analogous, and complementary. Price was identified at three points, including $\$ 24.99, \$ 49.99$, and $\$ 74.99$, consistent with a range of prices Texas consumers might expect to pay for a container this size and style. Amount of care information provided with the purchase was identified as 1) no information, 2) little information, or 3) extensive information. The little care information included information that is currently seen on care tags in the market today: exposure, fertilizing, and watering suggestions. The extensive care information included all of the information from the little information care tag and provided a picture of each plant and detailed pruning, deadheading, and factual information for individual plants in the container garden (Mason, 2007). Thus, the design was a $3 \times 3 \times 3$ factorial.

The number of combinations required was reduced from 27 to nine by using a partial factorial design. In reducing the number of combinations viewed, factor orthogonality (independence) was maintained and potential survey participant fatigue was decreased. Participants were asked to rate "how likely are you to purchase" each container garden on a 7 -point Likert scale $(1=$ very unlikely, $7=$ very likely) based on the color harmony, the price, and the amount of care information they were being provided. Conjoint and other statistical analyses were completed using SPSS 13.0 (SPSS, Chicago). Consumer preference was determined for the entire sample
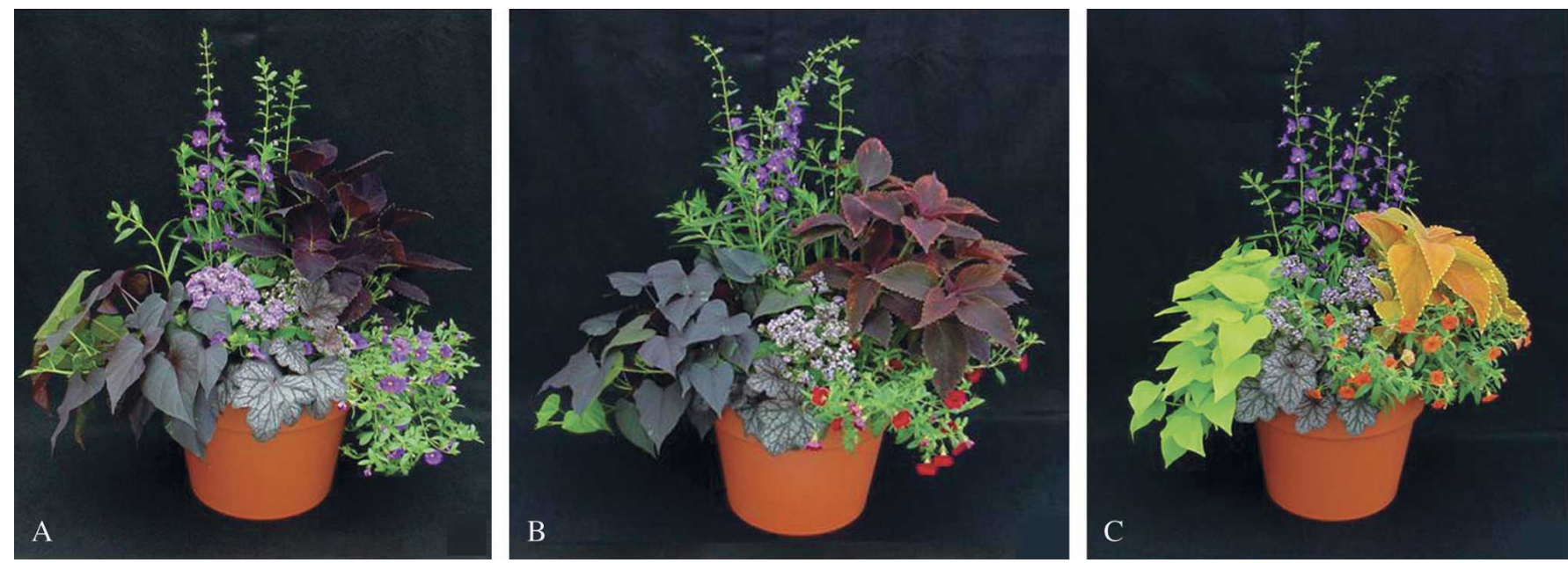

Fig. 1. Monochromatic (A), analogous $(\mathbf{B})$, and complementary $(\mathbf{C})$ container gardens photographed on 21 Apr. 2006 and used in the Web-based consumer preferences for container garden survey. Cultivars of Ipomoea batatas were 'Black Heart' (monochromatic and analogous) and 'Margarita' (complementary) Cultivars of Solenostemon scutellariodides were 'Merlot' (monochromatic), 'Religious Radish' (analogous), and 'Rustic Orange' (complementary) Cultivars of Calibrachoa $\times$ hybrida were 'Superbells Trailing Blue' (monochromatic), 'Superbells Red' (analogous), and 'Million Bells Crackling Fire' (complementary). The Heliotropium aborescens 'Nagano', Heuchera hybrid 'Velvet Night', and Angelonia angustifolia 'Angelface Blue' were kept the same for all color harmonies. 
and by gender within the participant population so that they could be compared numerically. Pearson's R was used as the test statistic at a significance level of $P \leq 0.05$.

For the analysis of the gardening experience and container garden use and maintenance sections of the survey, the participants were placed into one of three groups: nonusers, light users, and heavy users based on the number of container gardens that they either purchased or made and the distribution of the number of container gardens made or purchased across the entire sample. Nonusers had not purchased or created a container garden and were not used in these analyses, light users had purchased or made one to nine container gardens, and heavy users had purchased or made 10 or more container gardens. Light and heavy users were compared using the SPSS for Mac OS X Release 13.0 procedure "Crosstabs," which performs the Pearson's $\chi^{2}$ test. The series of questions that measured delight and repurchase intentions were analyzed using structural equation modeling using LISREL 8.7 (Lincolnwood, IL). Hicks et al. (2005) used structural equation modeling and showed that the path from delight (DEL) to repurchase intentions (PROREPUR) was $0.78(\mathrm{t}=5.44)$ to $0.90(\mathrm{t}=$ $10.90)$, indicating that customer delight was a strong indicator of intentions to make a subsequent purchase. The demographics section of the survey was analyzed using the SPSS procedure "Frequencies" to determine the descriptive statistics of these data, including frequencies and percentages.

An independent garden center assisted in sending out an e-mail invitation to complete the online survey to their customer e-mail list consisting of $\approx 7000$ customers. The same invitation was sent to 21 Texas Master Gardener coordinators across the state who then sent the survey to members of their chapters within the Texas Master Gardener program. In total, there were $\approx 5000$ Master Gardener volunteers who were invited to participate in the survey. The independent garden center provided a $\$ 5.00$ incentive to both their customers and the Master Gardeners for participating.

\section{Results}

There were 2042 attempted survey responses after $\approx 36 \mathrm{~h}$ and 985 were usable, i.e., all required questions in the survey were answered by the participant. Participant age ranged from 19 to 80 years with $79 \%$ of participants being 40 years of age or older and $21 \%$ younger than 39 years of age. Mean age was 50.4 years. Eighty-two percent of participants were female and $18 \%$ were male. Ninety-four percent of participants resided in a single-family dwelling and $6 \%$ lived in a condominium, duplex, triplex, or apartment. Ninety-four percent of the participants owned their home. Median household income fell in the category of $\$ 75,000$ or more. Sixty-three percent of participants had completed a Bachelor's degree or higher, whereas $99.5 \%$ had received at least a high school diploma or the equivalent. Ninetyfour percent of participants considered themselves at least sometimes time-stressed. The demographic profile is consistent with one presented by the National Gardening Association (2006) of a typical gardener being older than age 40 , female, and from an upper income household.

The heavy and light user population $(\mathrm{n}=$ 931) was compared with the overall participant population $(n=985)$ and no differences in demographics were found. By the definitions previously given, there were 54 nonconsumers $(5.4 \%), 364$ light consumers (36.9\%), and 567 heavy consumers $(57.5 \%)$. There was no significant difference in gen$\operatorname{der}\left(\chi^{2}=2.30, P=0.130\right)$ or income $\left(\chi^{2}=\right.$ $1.84, P=0.175)$ between heavy and light users. There was a significant difference in the age distribution $\left(\chi^{2}=7.37, P=0.007\right)$ between heavy and light users. More heavy users than light users were 40 years or older. There was also a difference between heavy and light users in home value $\left(\chi^{2}=12.12\right.$, $P=0.007)$. More heavy users had homes valued at $\$ 300,000$ or more than light users. No other demographic differences were found between heavy and light users. An individual with a higher home value likely has more opportunity for numerous container gardens, either from a higher income or larger home area. For the gardening experience and container gardening experience analyses, only heavy and light user responses were included.

Heavy and light users differed in years of gardening experience, time spent in the garden, and garden enjoyment. More heavy users had 11 to $21+$ years of gardening experience compared with light users, and more light users had zero to 10 years of gardening experience $\left(\chi^{2}=9.88, P=0.002\right)$. Heavy users indicated that they spent more time in the garden in spring than light users $\left(\chi^{2}=26.44, P=0.000\right)$. Heavy users enjoyed gardening more than light users $\left(\chi^{2}=13.56\right.$, $P=0.001)$. More light users dreaded spending time or were neutral to spending time in the garden than heavy users. Intuitively, heavy users may have a greater interest in gardening and thus have more gardening area, including container gardens.

Heavy and light users agreed on container garden use and maintenance. Eighty-four percent of heavy users and $82 \%$ of light users $\left(\chi^{2}=0.829, P=0.661\right)$ reported that they would very likely keep a container garden for the entire season in which they had purchased the container garden. Only $42 \%$ and $37 \%$ of heavy and light users $\left(\chi^{2}=3.92, P=0.141\right)$, respectively, said they would replace a container garden if it were to get overgrown or die during the season. More than $70 \%$ of heavy and light users $\left(\chi^{2}=4.43, P=0.109\right)$ indicated that they would be likely to purchase a plant pack full of new, seasonal plants when they needed to refresh overgrown or dead plants in their container garden(s). Ninety-six percent and $97 \%$ of heavy and light users $\left(\chi^{2}=0.477, P=0.490\right)$, respectively, reported that they had never used a professional service for container mainte- nance. Most were caring for their own container gardens and purchased them for an entire season, acknowledging there may be an opportunity to replace plants to refresh the container garden.

There was a significant difference $\left(\chi^{2}=\right.$ 16.12, $P=0.000$ ) between heavy and light users when asked whether they preferred to purchase a container garden preassembled or construct it on their own. Eighty-three percent of the heavy users said they preferred to make the container garden, whereas only $72 \%$ of the light users preferred this choice. A marketable distinction between these two groups emerges here. Individuals with few container gardens wanted to purchase them readymade, whereas individuals with multiple container gardens preferred to construct them at home, perhaps saving money and more definitely providing them with the opportunity to customize the container garden combination. There was a significant difference $\left(\chi^{2}=14.05, P=0.001\right)$ in preference for several species mixed in one container or several monoculture pots grouped together on a patio. More heavy users liked the mixed container and monoculture pots equally than light users. Light users, on the other hand, liked the monoculture pots grouped together more than heavy users.

Participants were shown a diagram that featured four panels of a container garden that was 1) prime, 2) overgrown, 3) pruned, and 4) recovered. They were then asked "how likely would you be to cut back or prune your container garden when it looks like the one picture in panel 2 if you knew you could get the results pictured in panel 4 ?" More than $85 \%$ of both heavy and light users reported that they would be willing to prune plants in their containers if they knew the outcome would be favorable $\left(\chi^{2}=0.069\right.$, $P=0.966)$ and indicated that they would use pruning directions if they were included in the care information $\left(\chi^{2}=0.832, P=0.660\right)$. There was no difference between the two groups as to whether they would be more likely to purchase a container garden if extensive care information was provided $\left(\chi^{2}=\right.$ $0.522, P=0.470$ ). Approximately $85 \%$ of both heavy and light users said they were willing to visit a Web site that would provide care information $\left(\chi^{2}=0.004, P=0.948\right)$.

Customer satisfaction, delight, and intentions to repurchase. When customer satisfaction, delight, and intentions to repurchase were measured, customers were, overall, delighted with their purchases of container gardens with a mean rating of 5.06/7.0 for the question "I am content with the purchase of my container" and a mean rating of 5.08 for the question "the outcome of my purchase was desirable." The path (Fig. 2) from customer delight $0.93(\mathrm{t}=49.02)$ strongly and positively influenced the customer's repurchase intentions $\left(\chi^{2}=8.29\right.$, df $=4, P=$ 0.082 , root mean square error of approximation $=0.033)$. In other words, customers delighted with their container gardens gave a strong indication that they will make subsequent purchases. As Hicks et al. (2005) found 


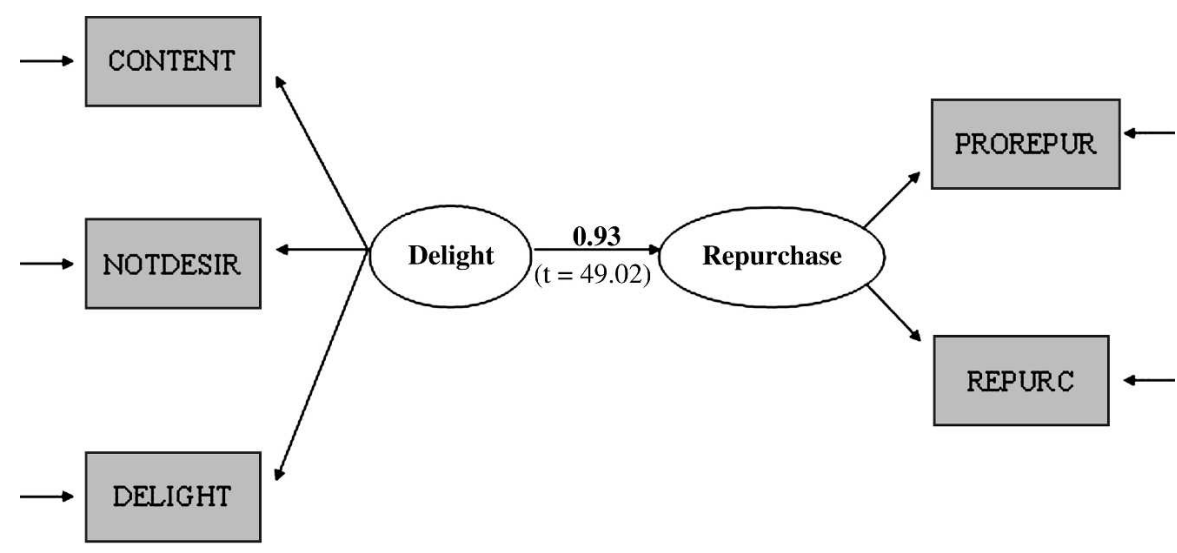

$\chi^{2}=8.29, \mathrm{df}=4, P=0.082, \mathrm{RMSEA}=0.033$

Fig. 2. Structural equation model for the effect of delight with a container garden purchase on repurchase intentions. Each of the rectangular boxes represents a question asked for this section of our survey. The three boxes on the left measured delight and the two on the right measured repurchase intentions. The effect of delight with a container garden on repurchase intentions is represented by the arrow between the ovals for delight and repurchase intentions (0.93). CONTENT $=\mathrm{I}$ am content with the purchase of this container garden: 1 (strongly disagree) to 7 (strongly agree); NOTDESIR = I would consider this container garden: 1 (very undesirable) to 7 (very desirable); DELIGHT $=$ My feelings toward this container garden can be described as: anger, frustration, disappointment, contentment, delight; PROREPUR $=$ The probability of me repurchasing this kind of container garden is: 1 (very low) to 7 (very high); REPUR = I will repurchase this kind of container garden the next time I want another one: 1 (disagree) to 7 (agree).

with indoor flowering potted plants, and also found here for container gardens, marketers need to go beyond meeting customer expectations and help provoke a "delight" reaction among their customer base.

Conjoint analysis. Only participants who completed the survey in its entirety were included in the conjoint analysis study ( $\mathrm{n}=$ 985). The conjoint design was significant and accounted for $99.8 \%$ of the variance in preference. The relative importance of the three factors studied decreased from price $(70.7 \%)$ to amount of care information provided with purchase $(22.9 \%)$ to color harmony $(6.4 \%)$ (Table 1). The most preferred container was a complementary color harmony with extensive care information and a price point of $\$ 24.99$ (mean rating $=4.58$ out of 7.0 ). The least preferred container was an analogous color harmony with no care information and a price point of $\$ 74.99$.

Women in this study placed a higher relative importance on price than men (Table 2). Men placed a higher relative importance on color harmony and valued the complementary color harmony more than women

Table 1. Relative importance and utility value for three levels of color harmony, price, and amount of care information provided with purchase in a conjoint study of consumer preferences for container gardens among 985 participants. $^{z}$

\begin{tabular}{llcc}
\hline Factor & \multicolumn{1}{c}{ Level } & Relative importance (\%) & Utility value \\
\hline Color harmony & Monochromatic & 6.4 & -0.0022 \\
& Analogous & & -0.1014 \\
& Complementary & & 0.1035 \\
Price & $\$ 24.99$ & 70.7 & 1.2738 \\
& $\$ 49.99$ & & -0.2957 \\
& $\$ 74.99$ & 22.9 & -0.9780 \\
Care information & None & & -0.3637 \\
& Little & & -0.0028 \\
& Extensive & & 0.3665 \\
\hline
\end{tabular}

${ }^{{ }^{2} R^{2}}=0.998, P=0.0000$.
Table 2. Relative importance (\%) by gender for color harmony, price, and amount of care information provided with purchase in a conjoint study of consumer preferences for container gardens among 985 participants.

\begin{tabular}{lcc}
\hline Factor & $\begin{array}{c}\text { Women } \\
(\mathrm{n}=812)\end{array}$ & $\begin{array}{c}\mathrm{Men}^{\mathrm{y}} \\
(\mathrm{n}=173)\end{array}$ \\
\hline Color harmony & 5.4 & 11.5 \\
Price & 72.3 & 62.2 \\
Care information & 22.3 & 26.3 \\
\hline
\end{tabular}

${ }^{\mathrm{z}} R^{2}=0.998, P=0.0000$

${ }^{\mathrm{y}} R^{2}=0.998, P=0.0000$.

hood to purchase one and would increase its value to them. Participants said they would be willing to visit a Web site that would provide detailed care instructions for container gardens. With most participants reporting that they planned on keeping their container gardens throughout the entire season, retailers providing pruning directions with their container gardens or on a Web site could guide their customers to success, avoiding purchase regret and perhaps improving the likelihood that a customer would be "delighted." Although it would take some time, the addition of care information to a Web site for a specific container garden is a cost-effective marketing strategy to potentially contribute to customer delight.

In addition, most of the participants reported that they would be willing to prune plants in their container gardens if they knew the outcome and they also reported that they would use pruning directions provided with the purchase. An online version of the care instructions could potentially be very detailed with video footage of pruning plants and pictures of how they grow back. Here, again, the Internet can provide the means for a cost-effective informational tool to help contribute to customer delight. This research suggests retailers should provide an effective way to deliver detailed care information to their customers if they want repeat patronage for their container gardens.

Consumers inherently have high expectations of horticultural products and, when or if they die, face disappointment. Participants in our study had a positive response to purchasing a plant pack to refresh senesced or overgrown plants in their container gardens. Offering an easy-to-carry plant pack of a variety of plant species that can replace senesced plant species in a container garden later in the season offers compensation to those who may be feeling disappointment with their container garden. With over $70 \%$ of participants in this study indicating that they would be likely or very likely to purchase the plant pack product, this may be a lucrative answer to counteract consumer regret or disappointment.

The more regret a consumer experiences, the less likely they are to repurchase products (Dennis et al., 2004). Our results were consistent with Hicks et al. (2005) that showed customer delight increased the likelihood a customer would make a repeat purchase. Although this indication was significant with a $P$ value of $\leq 0.082$, a strong relationship 
between delight and repurchase intention (0.93) was found.

Results from this study were not consistent with the tabletop Christmas tree study regarding the magnitude of the relative importance of price (Behe et al., 2005). The extremely high relative importance that our participants placed on price may have been because the range of prices in this study (\$24.99 to \$74.99) was much broader than the Christmas tree study ( $\$ 14.95$ to $\$ 24.95$ ). The high relative importance of price in this study was likely exaggerated because the perceivable range of prices investigated was much broader in comparison with the perceivable range of colors and amount of care information. In future studies in which color harmonies are being investigated, the use of an obnoxious, clashing color harmony may prove useful to increase the perceivable range that participants can identify. To a somewhat lesser extent, the same concept for the amount of care information used in future studies may also apply.

In contrast to this study, consumers in other conjoint studies, including edible flowers (Kelley et al., 2004), geraniums (Behe et al., 1999), and tabletop Christmas trees (Behe et al., 2005), indicated attributes other than price as the most important. It was predicted that price would not be the most important factor in choosing a container garden, but this was not the case, perhaps because the range for price was very broad and the perceived range for color was not.

The lowest utility value range in this study occurred in the color harmony attribute, which reveals that consumers perceived the difference in color harmonies shown in this study as the relatively least important attribute. Hardy et al. (2000) suggested that a small difference in utility value ranges may be the result of lack of knowledge to distinguish between factors, indifference, or difficulty in judging between them. It is possible that participants in our study were not knowledgeable of color harmonies. All of the container gardens that participants viewed for this study were very attractive and it may have proved difficult for participants to judge differences among them because anecdotal evidence shows color is very important to horticultural purchases. Flower color was an important attribute in consumer purchase decision-making in a geranium study (Behe et al., 1999) and in an edible flower study (Kelley et al., 2004). Most consumer preference studies reviewed investigated single color preferences, except the edible flower study (Kelley et al., 2004) in which color harmony preferences were studied. Participants in our study preferred the complementary color harmony most followed by the monochromatic and analogous harmonies, respectively. This was similar to an edible flower study in which consumers preferred a combination of all three colors studied (blue, yellow, and orange) over a monochromatic container of any one of these colors (Kelley et al., 2004).

Utility values indicate how valuable each of the attribute levels (color harmony, price, and amount of care information) was compared with the other attribute levels and how sensitive consumer preferences are to changes in product features (Orme, 2001). Converting utility values into monetary values is a common practice used for easier interpretation of data; however, it can also be misleading and can lead to poor advice for strategic planning (Orme, 2001). The value of each utility unit was calculated by dividing the range of the three prices ( $\$ 24.99$ to $\$ 74.99), \$ 50$, by the range of the utility values for the price points (1.2738 to -0.9780$)$, 2.2518. This results in each unit of utility being worth $\$ 22.20$. Multiplying the utility value that corresponds to the extensive information care tag determined that the extensive information added $\$ 8.14$, or $\approx 20 \%$, to the perceived value of the container garden. An extensive amount of care information may be a method for retailers to go beyond customer satisfaction to customer delight that Hicks et al. (2005) suggested. Although an initial investment would have to be made to develop and implement a method of delivery for the extensive amount of care information that customers want, it could potentially increase profits.

We found that using an Internet survey proved to be successful because the response to our survey invitation was overwhelming. Our participants were $82 \%$ female with a mean age of 50 years. They generally owned a single-family home and their median income fell in the $\$ 75,000$ or greater range. All participants had finished high school and $63 \%$ held a Bachelor's degree or higher. Because there were few significant differences between heavy and light users, in both demographics and attitudes about container gardens, a uniform marketing plan should be useful for container gardens. Participants indicated that the most important attribute of the three we studied was price, followed by amount of care information provided with the purchase, and finally color harmony. Therefore, any of the color harmonies used in this study can be marketed equally and extensive care information should be included in the overall marketing plan. Future extensions of this study should incorporate a sample that is representative of the U.S. population. Behe (2006) used Knowledge Networks, a company who conducts survey research for clients such as Stanford University and CBS News to provide a scientific probability sample of U.S. households. This type of company would be effective with this issue.

\section{Literature Cited}

Behe, B.K. 1993. Floral marketing and consumer research. HortScience 28:11-14.

Behe, B.K. 2006. Conjoint analysis reveals consumers prefer long, thin asparagus spears. HortScience 41:1259-1262.

Behe, B.K., B.M. Cregg, M.W. Duck, K.M. Kelley, and R.M. Walden. 2005. Consumer preferences for tabletop Christmas trees. HortScience 40: 409-412.

Behe, B.K., R. Nelson, S. Barton, C. Hall, C. Safley, and S. Turner. 1999. Consumer pref- erences for geranium flower color, leaf variegation and price. HortScience 34:740 742 .

Cobanoglu, C., B. Warde, and P.J. Moreo. 2001. A comparison of mail, fax and Web-survey methods. Intl. J. Mkt. Res. 43:441-452.

Container Gardening Associated. 2005. Gardens in containers and planters: Explore container gardening. 28 May 2007. <http://www.containergardens.com $/>$

Dennis, J.H., B.K. Behe, T.J. Page, Jr., and R.A. Spreng. 2004. Can experiencing regret affect future consumer consumption of horticultural products? Acta Hort. 655:89-91.

Frank, C.A., R.G. Nelson, E.H. Simonne, B.K. Behe, and A.H. Simonne. 2001. Consumer preferences for color, price, and vitamin $\mathrm{C}$ content of bell peppers. HortScience 36:795-800.

Gaasbeek, A.F. and V.C. Bouwman. 1991. Conjoint analysis in market research for horticultural products. Acta Hort. 295:121-125.

Hardy, J., S.S. Barton, B.K. Behe, J. Brooker, R.T. Fernandez, C.R. Hall, M.T. Haque, R. Hinson, P. Knight, R. McNiel, K. Muzii, T.J. Page, D.B. Rowe, C. Safley, and R.E. Schutzki. 2000. Consumers preferences for plant size, type of plant material and design sophistication in residential landscaping. J. Environ. Hort. 18: 224-230.

Hicks, J.M., T.J. Page, Jr., B.K. Behe, J.H. Dennis, and R.T. Fernandez. 2005. Delighted consumers buy again. J. Consumer Satisfaction, Dissatisfaction and Complaining Behavior. 18: 94-104.

Internet World Stats. 2006. United States of America. Internet usage and broadband usage report. 29 May 2007. <http://www.internetworldstats. com/am/us.htm>.

Kelley, K.M., B.K. Behe, J.A. Biernbaum, and K.L. Poff. 2004. Consumer and professional chef perceptions and acceptance of edible flowers. Acta Hort. 633:475-479.

Mason, S. 2007. Consumer preferences for price, color harmony and care information of container gardens. Texas A \& M Univ., College Station, MS Thesis.

McCullough, D. 1998. Web-based market research: The dawning of a new age. Direct Marketing 61:36-38.

Miller, C. 2001. Surveys reveal container gardening popularity. National Gardening Association, South Burlington VT. Aug. 2006. <http://www. greenbeam.com/features/tour021901a.stm>.

Moskowitz, H.R., R. Katz, J. Beckley, and H. Ashman. 2004. Understanding conjoint analysis. Food Technol. 58:35-38.

National Gardening Association. 2006. 2005 National gardening survey. Natl. Gardening Assn., Burlington, VT.

Orme, B.K. 2001. Assessing the monetary values of attribute levels with conjoint analysis: Warnings and suggestions. Sawtooth Software Inc., Sequim, WA.

Simonne, A.H., B.K. Behe, and M.M. Marshall. 2006. Consumers prefer low-priced and highlycopene-content fresh-market tomatoes. HortTechnology 16:674-681.

Singh, S.P. 1999. The changing structure of the U.S. green industry: Factors influencing opportunities and issues. J. of Intl. Food and Agribusiness Mktg. 10:65-83.

Starman, T.W. 2005. Vegetative annuals: Guide to growing and container gardens. Meister Media, Willoughby, $\mathrm{OH}$.

Starman, T.W. and K. Pufahl. 2002. Tips on designing, growing and marketing mixed baskets and containers. O.F.A. Services Inc., Columbus, $\mathrm{OH}$. 